\title{
The effect of nitro-oxidative stress on platelet aggregability in migraine patients in a Rehabilitation Hospital - a pilot study
}

Adriana Elena Bulboaca, ${ }^{1,2}$, Mihai Blidaru', Gabriela Dogaru ${ }^{1,2}$, Ioana Stanescu ${ }^{1,2}$, Alexandra Ina Bulboaca ${ }^{1}$

Corresponding author: Gabriela Dogaru, E-mail address: dogarugabrielaumf@gmail.com

\begin{abstract}
Introduction: Migraine is a common, chronic and disabling neurovascular disorder that is characterized by severe headache attacks. Pathogenesis of migraine is still unclear, different vascular, neurological, and neuroinflammatory mechanisms have been suggested. Nitric oxide (NO) plays a role during trigeminovascular inflammation associated with migraine attacks, and increased production can lead to increased platelet aggregability. Methods: 37 patients with migraine attack were compared with a control group (37 healthy subjects). Nitro-oxidative stress was evaluated by plasma determination of NO metabolites (NOx). Platelet aggregability was measured using a spectrophotometrically method with an aggregometer. Results: migraine patient group showed a significantly increased production of NOx and platelet aggregability. There was also of positive correlation between these two parameters. Inflammatory reaction was also present in migraine patients (C reactive protein significantly increased in migraine group patients compared with control group). Conclusions: In conclusion, increased platelet aggregability and NO levels in migraine patients support the roles of nitro-oxidative stress and endothelial dysfunction in migraine pathogenesis.
\end{abstract}

Key words: migraine, nitric oxide, platelet aggregability, inflammation, pain,

\section{Introduction}

Migraine is a painful neurological disease whose manifestation results from an interplay of envirogenomic factors and various triggers [1]. The clinical features of migraine according to International Headache Society classification include intense, pulsating head pain localized to one side of the head that can effectively disable for up to $72 \mathrm{~h}$ [2]. Accompanying symptoms of migraine in addition to the headache include nausea, vomiting, and hypersensitivity to lights, sounds and/or smells, all of which can be aggravated by physical activity [2].

Nitric oxide (NO) plays an important role in the control of vascular reactivity, cerebral blood flow and neuronal activity . It is also well known for its ability to relax blood vessels and in addition has many other biological effects. NO generated by endothelial NO synthase (eNOS) may have an important role in vasodilatation involved in migraine pathophysiology [3]. NO generated in the migraine attack may also induce neuronal death due to nitro-oxidative stress [4]. NO is synthesized from L-arginine by nitric oxide synthase (NOS) wich requires NADPH and molecular oxygen. Constitutional forms of NOS are endothelial (eNOS) and neuronal (nNOS), whilst in inflammation an inducible form (iNOS) is produced in activated macrophages, and other cell types [5]. NO itself is a short-lived, highly reactive species but is major products nitrate and nitrite (collectively termed NOx) can readily be measured retrospectively in biological samples as markers of nitric oxide production. The active NO level was reported to increase under enhanced oxidative stress. NO level might be a good parameter for endothelial dysfunction under oxidative stress. Platelet activation is also common in inflammatory process associated with oxidative stress, that can lead to increased thrombosis risk [6]. Increased platelet aggregability can constitute an important risk factor for stroke [7].

The objective of this study was to investigate the endothelial function (EF) expressed by nitric oxide synthesis in patients with migraine and to observe if there is a correlation between nitro-oxidative stress and platelet aggregability.

\section{Methods}

37 patients with migraine attack were compared with a control group (37 healthy subjects). None of the subjects used antiplatelet therapy. The study was conducted in accordance with the Helsinki Declaration and an informed consent was signed by each patient. Nitro-oxidative stress was evaluated by plasma determination of NO metabolites (NOx). Total nitrate and nitrite (NOx) were measured in plasma by Griess method. Platelet aggregability was measured using a spectrophotometrically method with an aggregometer. As agonist, adenosine-5 diphosphate (ADP) was used because it is common and useful in clinical practice. The final ADP 
concentration for platelet aggregability testing was $1.0 \mu \mathrm{mol} / \mathrm{L}$. The grading curve (GC) was used as index of platelet aggregability, and was graded into three levels according to GC type: suppressed aggregability level with GC type -2 or -1 , the normal aggregability level with GC type 0 or +1 , and accelerated aggregability level with $\mathrm{GC}$ type +2 or + 3 . NOx and platelet aggregability were determined during the first 6 hours of migraine attack.

Statistical analysis

The data were analyzed using Statistical program, and presented as mean \pm SD. For non parametric values Chi square test was used for groups comparisons. For parametric values with normal distribution, $\mathrm{t}$ Student test was used and for non-normal distribution ManWhitney test served for comparisons. $p<0.01$ was considered statistical significant. Pearson test was used for determination of the correlation between parameters.

\section{Results}

The baseline characteristics of the patients (age, gender, body mass index, fasting bloid sugar, plasma lipids status, blood pressure values, smoking status, inflammatory parameters) are represented in table 1 . The baseline characteristics assessment showed a significantly increased of the number of smokers patients compared with non-smokers. There was also a significantly increased plasma level of CRP in migraine patients group compared with control group. The NO production was significantly increased in migraine patients group compared with control group $(\mathrm{p}<0.01)$. NOx $(\mathrm{mmol} / \mathrm{L})$ had the following values : control group $=68,76 \pm 6.166$; migraine group $=$ $83.66 \pm 5.5(\mathrm{p}<0.001)$. A positive correlation was also found between NO production and increased platelet aggregability, correlation coefficient by Person test $(\mathrm{r})=+0,75$. No correlation was found between platelet aggregability and CRP.

Platelet aggregability in migraine patients compared with control group is represented in table 2 .

Platelet aggregability was significantly accelerated in migraine group compared with control group ( $\mathrm{p}$ $<0.00001)$.

Table 1 - Baseline characteristics of the patients compared with control group

\begin{tabular}{|l|l|l|}
\hline & Control Group & Migraine group \\
\hline Number of the subjects & 37 & 37 \\
\hline Age & $41.34 \pm 4.45$ & $40.56 \pm 2.33$ \\
\hline Gender (men/women) & $17 / 20$ & $11 / 26$ \\
\hline Fasting blood sugar (mg/dL) & $96.33 \pm 5.44$ & $98.45 \pm 4.23$ \\
\hline Hyperlipemia (number of patients) & 7 & 10 \\
\hline Blood pressure (mmHg) & & \\
-systolic & $123.67 \pm 7.66$ & $127.5 \pm 6.23$ \\
-diastolic & $81.33 \pm 3.66$ & $87.33 \pm 6.5$ \\
\hline Smoking status & & 16 \\
- non smoker & 29 & 7 \\
-former smoker & 5 & $14 *$ \\
\hline -smoker & 3 & $26.66 \pm 3.32$ \\
\hline Body mass index (BMI) & $24.45 \pm 3.45$ & $1.88 \pm 0.5 * *$ \\
\hline C reactive protein (CRP)(mg/dL) & $0.45 \pm 0.1$ & $287.33 \pm 11.33$ \\
\hline Fibrinogen (mg/dL) & $234.55 \pm 10.22$ & \\
\hline
\end{tabular}

${ }^{*} \mathrm{p}<0.001$ (chi square test), ${ }^{* *} \mathrm{p}<0.01 \mathrm{t}$ Test

Table 2 - Platelet aggregability in migraine patients compared with control group

\begin{tabular}{|l|l|l|l|}
\hline Groups & Platelet aggregability & Accelerated \\
\hline & Normal & Suppressed & A \\
\hline Migraine group* & $3(18.50)[12.99]$ & $1(1.00)[0.00]$ & $33(17.50)[13.73]$ \\
\hline Control group & $34(18.50)[12.99]$ & $1(1.00)[0.00]$ & $2(17.50)[13.73]$ \\
\hline
\end{tabular}




\section{Discussions}

The NO production usually produces a protective effect to the endothelial cells on the vessels wall, that can constitute a protective mechanism against cerebral ischemia [8]. The inflammatory reaction associated with migraine attacks leads to increased NO production, above the physiological level, due to oxidative stress, that can have, as a long term consequence, an endothelial dysfunction and further to contribute to increased platelet aggregability [9]. The inflammatory reaction is present in our migraine patients, proved by the significantly increased CRP plasma vales (see Table 1). An important contributor to inflammatory reaction can be smoking status [10]. We also found a significant increase of the number of current smokers in migraine group compared with control group (see Table 1). There are two factors that can inhibit the clinical efficacy of organic nitrates: the hypo-responsiveness to NO of de novo tissue ("NO resistance"), detected in blood vessels as well as at platelet level [11] and "nitrate tolerance", which implies a continuous decrease of responsiveness during chronic therapy, detected mainly in blood vessels [12] although it can take place in platelets as well [13]. Nevertheless, some studies show that there are circumstances in which increased oxidative stress and release of superoxide anion are related to tolerance induction. The result is the scavenging of NO regardless of its provenience (exogenous or endogenous) leading to cross-tolerance between nitrates, whether they derive from NO donors (sodium triprusside) or produced by the endothelium [14]. Therefore it is possible that desensitization of platelets to NO is the cause of vascular nitrate tolerance [15].

On the basis of experimental studies in rats with migraine induced by intravenous infusions of nitroglycerin (an exogenous nitric oxide donor) and histamine (which liberates nitric oxide from vascular endothelium), it has been suggested that nitric oxide is a likely candidate responsible molecule [16]. This evidence suggests that the release of nitric oxide from blood vessels, perivascular nerve endings or from brain tissue is an important molecular trigger mechanism in spontaneous headache pain [17]. Increased NO production in migraine patients as it is demonstrated by our results, can constitute an important contributor to nitro-oxidative stress associated with migraine attack, and was also proved by experimental induced migraine [3, 16]. NO may function as a signal molecule in controlling neuronal activity and is important in controlling sensory inputs during migraine attack and interacting with reactive oxygen substances (ROS), which may induce headache through changes of cerebral blood flow [18]. It is suggested that NO could be an important mediator in the initiation or the propagation of a neurogenic cranial vessel inflammatory response that might eventually result in a migraine attack [19]. Therefore, oxidative stress parameters such is malondialdehyde (MDA) and nitro-oxidative stress parameters (NO metabolites) may serve as useful markers to show the increased vulnerability to nitrosative and oxidative stress in migraine patients [20].

On the other hand, during a migraine attack, serotonin is released from activated platelets into blood plasma causing a short-lived increase in free plasma serotonin that raises serotonin levels in the brain [21]. Raised levels of serotonin in the brain exert a vasoconstrictor effect on intracerebral arteries initiating the aura phase and cerebral ischemia and, as a consequence, transitive visual disturbances, that can manifest as floaters, hemianopsia, or lightening [22, 23]. At high concentrations, serotonin may cause vasoconstriction and, consequently, the neuronal signs of aura, whereas at low concentrations, it may already stimulate perivascular pain fibres and cause vasodilatation via local formation of nitric oxide, prostaglandins, and neuropeptides [24]. A reactive oxidant produced from $\mathrm{NO}$ and superoxide anion at the site of inflammation, peroxynitrite (ONOO-) has effects including changes in platelet membrane activity and fluidity. Migraine patients proved to have intercritic changes in platelet membrane fluidity and activity that may be related to the oxidative stress caused by increased ONOO- levels [25]. Previous research supports the hypothesis of an activation of the L-arginine/NO pathway in migraine patients, especially those with aura, and demonstrated an increased level of L-arginine (an NO donor) in platelets of migraine patients studied in headache free-periods [26]. Blockade of nitric oxide synthase (NOS) by $\mathrm{N}(\mathrm{G})$-Nitro-L-arginine methyl ester effectively treats attacks of migraine without aura. Similar results have been obtained for chronic tension-type headache and cluster headache. Inhibition of the breakdown of cyclic guanosine monophosphate (cGMP) also provokes migraine in sufferers, indicating that the cGMP molecules are the 
effectors of NO-induced migraine [27]. Indeed, selective n-NOS and i-NOS inhibitors are already in early clinical development [28]. Additionally, it is suggested that intranasal hydroxocobalamin, a NO scavenger, may have a prophylactic effect in migraine [29]. Being an important risk factor for cardiovascular and cerebro-vascular diseases [30, 31 , migraine can constitute a real target for new therapies that can also reduce the morbidity for stroke and other vascular diseases.

\section{Conclusions}

NO contributes to the migraine pathophysiology inducing associated vasodilatation. Correlation between increased NO production and platelet activation can contribute to the increased risk for cerebral ischemia in migraine patients. Inhibition of NO production or blockade of steps in the NO-cGMP pathway or scavenging of NO may be targets for new drugs for treating migraine and other headaches. Further clinical and biochemical studies are needed to investigate the associations between pathophysiology of migraine and ischemic stroke in order to be able to develop new therapies for migraine and new prophylactic methods for ischemic stroke.

\section{References}

1. Gasparini CF, Sutherland HG, Griffiths LR, Studies on the pathophysiology and genetic basis of migraine, Curr Genomics, 2013;14(5):300-315.

2. IHS The international classification of headache disorders, 3rd edition (beta version) Cephalalgia, 2013;33(9):629-808.

3. Bulboacă AE, Bolboacă SD, Stănescu IC, Sfrângeu CA, Bulboacă AC, Preemptive Analgesic and Antioxidative Effect of Curcumin for Experimental Migraine. Biomed Res Int ;2017:4754701. doi: $10.1155 / 2017 / 4754701$

4. Pradhan AA, Bertels Z, Akerman S, Targeted Nitric Oxide Synthase Inhibitors for Migraine, Neurotherapeutics, 2018 Mar 7. doi: 10.1007/s13311-018-0614-7.

5. Ghasemi M, Mayasi Y, Hannoun A, Eslami SM, Carandang R, Nitric Oxide and Mitochondrial Function in Neurological Diseases, Neuroscience, 2018, 15; 376:48-71.
6. Walford G, Loscalzo J, Nitric oxide in vascular biology, J Thromb Haemost, 2003;1(10):21128.

7. Bulboaca CA, Bulboaca AE, Prodan C, Platelet activation and nitric oxide synthesis in patients with transient ischemic attack, Neurology, 2011, 76(9): 424-425.

8. Iadecola $\mathrm{C}$, Anrather $\mathrm{J}$, The immunology of stroke: from mechanisms to translation. Nat Med, 2011;17:796-808.

9. Garcia-Bonilla L, Moore JM, Racchumi G, Zhou P, Butler JM, Iadecola C, Anrather J, Inducible nitric oxide synthase in neutrophils and endothelium contributes to ischemic brain injury in mice, J Immunol, 2014;193(5):25317.

10. McEvoy JW, Nasir K, DeFilippis AP, Lima JA, Bluemke DA, Hundley WG, Barr RG, Budoff MJ, Szklo M, Navas-Acien A, Polak JF, Blumenthal RS, Post WS, Blaha MJ.Arterioscler Thromb Vasc Biol, Relationship of cigarette smoking with inflammation and subclinical vascular disease: the Multi-Ethnic Study of Atherosclerosis ;35(4):1002-10.

11. Chirkov YY, Chirkova LP, Horowitz JD, Suppressed anti-aggregating and cGMPelevating effects of sodium nitroprusside in platelets from patients with stable angina pectoris, Naunyn Schmiedebergs Arch Pharmacol,1996;354:520-525.

12. Sage PR, de La Lande IS, Stafford I, Bennett CL, Phillipov G, Stubberfield J, Horowitz JD. Nitroglycerin tolerance in human vessels: evidence for impaired nitroglycerin bioconversion, Circulation, 2000;102:2810 2815.

13. Chirkov YY, Chirkova LP, Horowitz JD, Nitroglycerin tolerance at the platelet level in patients with angina pectoris, Am J Cardiol, 1997;80:128-131.

14. Munzel T, Sayegh H, Freeman BA, Tarpey MM, Harrison DG, Evidence for enhanced vascular superoxide anion production in nitrate tolerance. A novel mechanism underlying tolerance and cross-tolerance, J Clin Invest, 1995;95:187-194. 
15. Holmes AS, Chirkov YY, Willoughby SR, Poropat S, Pereira J, Horowitz JD, Preservation of platelet responsiveness to nitroglycerine despite development of vascular nitrate tolerance, $\mathrm{Br} \mathrm{J}$ Clin Pharmacol, 2005 ;60(4):355-63.

16. Bulboacă AE, Bolboacă SD, Stănescu IC, Sfrângeu CA, Porfire A, Tefas L, Bulboacă AC, The effect of intravenous administration of liposomal curcumin in addition to sumatriptan treatment in an experimental migraine model in rats. Int J Nanomedicine, 2018; 13:3093-3103.

17. Thomsen LL, Olesen J, Nitric oxide in primary headaches, Curr Opin Neurol, 2001;14(3):31521.

18. Ciancarelli I, Tozzi-Ciancarelli MG, Di Massimo C, Olivieri L, Carolei A, Preventive non-pharmacological treatment and nitric oxide in chronic migraine, $\mathrm{J}$ Headache Pain, 2005;6:341-342.

19. Napoli R, Guardasole V, Zarra E, Matarazzo M, D'Anna C, Saccà F, Affuso F, Cittadini A, Carrieri $\mathrm{PB}$, Saccà L, Vascular smooth muscle cell dysfunction in patients with migraine, Neurology, 2009;72:2111-2114.

20. Yilmaz G, Sürer H, Inan LE, Coskun O, Yücel $\mathrm{D}$, Increased nitrosative and oxidative stress in platelets of migraine patients, Tohoku J Exp Med, 2007 ;211(1):23-30.

21. Danese E, Montagnana M, Lippi G, Platelets and migraine, Thromb Res, 2014;134(1):17-22.

22. Gasparini CF, Smith RA, Griffiths LR, Genetic and biochemical changes of the serotonergic system in migraine pathobiology, J Headache Pain. 2017; 18(1): 20, doi: 10.1186/s10194016-0711-0

23. Bulboaca AE, Dogaru G, Mihai Blidaru, Bulboaca AC, Stanescu I, Evaluation of oxidative stress in migraine patients with visual aura - the experience of an Rehabilitation Hospital, Balneo Research Journal. 2018;9(3):303-308.

24. Borgdorff P, Tangelder GJ, Migraine: possible role of shear-induced platelet aggregation with serotonin release, Headache, 2012;52(8):1298318.
25. Taffi R, Vignini A, Lanciotti C, Luconi R, Nanetti L, Mazzanti L, Provinciali L, Silvestrini M, Bartolini M, Platelet membrane fluidity and peroxynitrite levels in migraine patients during headache-free periods, Cephalalgia, 2005 ; 25(5):353-8.

26. Gallai V, Floridi A, Mazzotta G, Codini M, Tognoloni M, Vulcano MR, Sartori M, Russo S, Alberti A, Michele F, Sarchielli P, Larginine/nitric oxide pathway activation in platelets of migraine patients with and without aura, Acta Neurol Scand. 1996 ; 94(2):151-60.

27. Olesen $\mathrm{J}$, The role of nitric oxide (NO) in migraine, tension-type headache and cluster headache, Pharmacol Ther, 2008 ;120(2):15771.

28. Olesen $\mathrm{J}$, Nitric oxide-related drug targets in headache, Neurotherapeutics, 2010;7(2):18390

29. Kuy PH, Merkus FW, Lohman JJ, Berg JW, Hooymans PM, Hydroxocobalamin, a nitric oxide scavenger, in the prophylaxis of migraine: an open, pilot study. Cephalalgia, 2002; 22:513-519.

30. Bigal ME , Kurth T, Santanello N, Buse D, Golden W, Robbins M, Lipton RB, Migraine and cardiovascular disease: a population-based study, Neurology, 2010, 23;74(8):628-35.

31. Bulboacă AE, Bolboacă SD, Bulboacă AC, Prodan CI, Association between low thyroidstimulating hormone, posterior cortical atrophy and nitro-oxidative stress in elderly patients with cognitive dysfunction. Arch Med Sci, $2017 ; 13(5): 1160-1167$. 